\title{
The Soft Magnetic Properties and Temperature Stability of $\mathrm{Co}-\mathrm{Fe}-\mathrm{Zr}-\mathrm{B}$ Metallic Glasses
}

\author{
J. BednarČÍK ${ }^{a, b, *}$, J. KováČ ${ }^{c}, \mathrm{~S} \operatorname{Roth}^{d}$, J. FÜzer ${ }^{b}$, \\ P. KOLlÁR ${ }^{b}$, L.K. VARGA ${ }^{e}$ AND H. FrAnZ ${ }^{a}$ \\ ${ }^{a}$ Deutsches Elektronen Synchrotron (HASYLAB) \\ Notkestr. 85, 22607 Hamburg, Germany \\ ${ }^{b}$ Institute of Physics, Faculty of Science, P.J. Šafárik University \\ Park Angelinum 9, 04154 Košice, Slovakia \\ ${ }^{c}$ Institute of Experimental Physics, Slovak Academy of Sciences \\ Watsonova 47, 04001 Košice, Slovakia \\ ${ }^{d}$ IFW Dresden, Institut für Metallische Werkstoffe \\ Helmholtzstr. 01069 Dresden, Germany \\ ${ }^{e}$ RISSPO, Hungarian Academy of Sciences \\ P.O. Box 49, 1525 Budapest, Hungary
}

In the present work multicomponent Co-based alloys with nominal composition $\mathrm{Co}_{72-x} \mathrm{Fe}_{x} \mathrm{Zr}_{8} \mathrm{~B}_{20}(x=10,15$, and 20 at.\%) were synthesized by single-roller melt-spinning. The measurement of coercivity, $H_{\mathrm{c}}$, reveals the soft magnetic behavior of investigated alloys. The value of $H_{\mathrm{c}}$ increases from $23 \mathrm{~A} / \mathrm{m}$ for alloy with $x=10$ at. $\%$ up to $32 \mathrm{~A} / \mathrm{m}$ for alloy with $x=20$ at. $\%$. Further it was found that crystallization temperature of as-quenched alloys slightly varies with iron content and lays between 605 and $625^{\circ} \mathrm{C}$. From the temperature dependence of magnetization it follows that partial substitution of cobalt by iron has positive influence on the Curie temperature of amorphous phase, $T_{\mathrm{c}}^{\mathrm{am}}$, which increases from $300^{\circ} \mathrm{C}$ up to $462^{\circ} \mathrm{C}$ for alloy with $x=10$ at. $\%$ and $x=20$ at. $\%$, respectively.

PACS numbers: $61.10 . \mathrm{Nz}, 75.50 . \mathrm{Kj}$

\section{Introduction}

Over the past several decades, melt-spun Co-based amorphous alloys, with their high permeability and zero magnetostriction, have been extensively investi-

*corresponding author; e-mail: jozef.bednarcik@desy.de 
gated for applications in magnetic devices requiring magnetically soft materials [1]. Furthermore, many studies have been carried out during the last decade aiming at the preparation of bulk metallic glasses. Recently, Inoue et al. found some bulk amorphous alloys in $\mathrm{Co}-\mathrm{Fe}-(\mathrm{Zr}, \mathrm{Nb}, \mathrm{Ta})-\mathrm{B}$ system, which combine a large glass forming ability with promising magnetic and mechanical properties [2]. The aim of the present work is to explore thermal stability of amorphous soft magnetic $\mathrm{Co}-\mathrm{Fe}-\mathrm{Zr}-\mathrm{B}$ alloys. The obtained results will guide further material processing aimed at the preparation of bulk amorphous materials by hot powder compaction.

\section{Experimental}

Multicomponent Co-based amorphous alloys with nominal composition $\mathrm{Co}_{72-x} \mathrm{Fe}_{x} \mathrm{Zr}_{8} \mathrm{~B}_{20}(x=10,15$, and 20 at.\% $)$ were synthesized by means of single-roller melt-spinning. High-energy X-ray diffraction (XRD) measurements were performed at HASYLAB at DESY (Hamburg, Germany) on the undulator beamline PETRA 2 at PETRA storage ring using monochromatic synchrotron radiation of $112 \mathrm{keV}(\lambda=0.110696 \AA)$. The samples measured at room temperature were illuminated for 30-60 s by well collimated incident beam having cross-section of $1 \times 1 \mathrm{~mm}^{2}$. XRD patterns were collected using a two-dimensional (2D) MAR345 imaging plate detector. The background intensity was subtracted directly from 2D XRD pattern, and the result was integrated to the $Q$-space $(Q=4 \pi \sin (\theta) / \lambda)$ using the software package FIT2D [3]. The coercivity, $H_{\mathrm{c}}$, of as-quenched alloys was determined from hysteresis loops measured at room temperature with a DC-hysteresis graph. The thermal stability of investigated alloys was studied by differential scanning calorimetry (DSC) using a NETZSCH DSC 404. The corresponding crystallization temperatures, $T_{x}$, were determined from DSC scans traced at constant heating rate of $20^{\circ} \mathrm{C} / \mathrm{min}$ under vacuum. The temperature dependence of specific magnetization, $\sigma(T)$, was measured using a Faraday magnetic balance. The Curie temperature, $T_{\mathrm{c}}^{\mathrm{am}}$, was inferred from inflexion point in $\sigma(T)$ curve, traced at constant heating rate of $10^{\circ} \mathrm{C} / \mathrm{min}$.

\section{Results and discussion}

The as-quenched samples exhibit the diffuse scattering patterns (Fig. 1a) typical of metallic glasses with a maximum at $Q \approx 3.05 \AA^{-1}$ and pronounced oscillations visible up to $Q \approx 19 \AA^{-1}$. As can be seen from Fig. 1a, partial substitution of cobalt by iron does not significantly change the shape and position of $\mathrm{X}$-ray diffraction patterns, and thus indicate rather weak influence on local atomic arrangement. It is due to fact that Co and Fe atoms are very similar in the sense of their atomic radii $\left(r_{\mathrm{Co}}=1.253 \AA, r_{\mathrm{Fe}}=1.241 \AA\right)$ and form factors, which do not differ significantly. Figure $1 \mathrm{~b}$ shows DSC scans of as-quenched CoFeZrB alloys. All corresponding scans exhibit only one sharp exothermic peak indicating one-step crystallization event within the investigated temperature range. The position of this peak slightly varies with iron content and lies between 605 and 

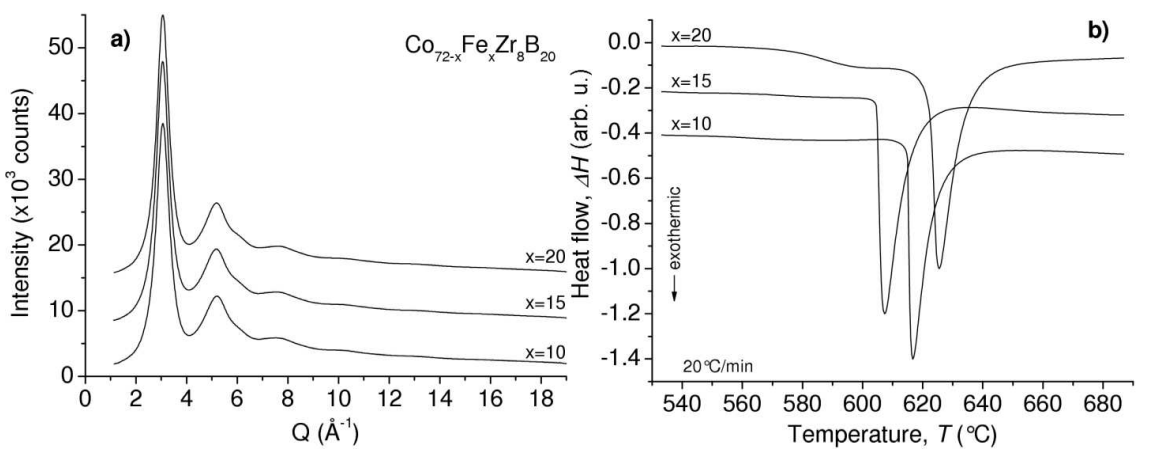

Fig. 1. (a) XRD patterns and (b) DSC scans of as-quenched CoFeZrB alloys.

\section{TABLE}

The coercivity, $H_{\mathrm{c}}$, Curie temperature, $T_{\mathrm{c}}^{\mathrm{am}}$, and crystallization temperature, $T_{x}$, of amorphous $\mathrm{Co}_{72-x} \mathrm{Fe}_{x} \mathrm{Zr}_{8} \mathrm{~B}_{20}(x=10$, 15 , and 20 at.\%) alloys.

\begin{tabular}{c|c|c|c}
\hline \hline$x$ [at.\%] & $H_{\mathrm{c}}[\mathrm{A} / \mathrm{m}]$ & $T_{\mathrm{c}}^{\mathrm{am}}\left[{ }^{\circ} \mathrm{C}\right]$ & $T_{x}\left[{ }^{\circ} \mathrm{C}\right]$ \\
\hline 10 & $23 \pm 1$ & $300 \pm 2$ & $612 \pm 2$ \\
15 & $26 \pm 1$ & $390 \pm 2$ & $605 \pm 2$ \\
20 & $32 \pm 1$ & $462 \pm 2$ & $625 \pm 2$
\end{tabular}

$625^{\circ} \mathrm{C}$ (see Table). The lack of any traces of peaks in the second heating DSC run up to $900{ }^{\circ} \mathrm{C}$ (not shown here) indicates that all phase transformations were accomplished during the first run. The samples with $x=10$ and 15 at.\% reveal the presence of a supercooled liquid region. In case of sample with $x=20$ at.\% it is less pronounced due to appearance of weak and relatively broad exothermic pre-crystallization peak. The measurement of coercivity, $H_{\mathrm{c}}$, of the as-quenched alloys reveals their soft magnetic nature. Furthermore, the thermomagnetic measurements on as-quenched ribbons (see Fig. 2a) indicate an enhancement of the saturation magnetization and Curie temperature of amorphous phase with partial substitution of cobalt by iron. The obtained data are collected in Table. The appearance of the relatively high and sharp step in the $\sigma(T)$ curves above $600^{\circ} \mathrm{C}$ reveals that the crystallization of the amorphous phase results in the formation of at least one ferromagnetic phase with a Curie temperature higher than the crystallization temperature. In order to identify the phase composition of crystallized alloys, the samples after two heating runs up to $900^{\circ} \mathrm{C}$ (performed during DSC scans) were inspected with XRD. As can be seen from XRD patterns collected in Fig. 2b, the addition of Fe has an significant impact on phase composition of crystallized alloys. In case of alloy with the highest iron content ( $x=20$ at.\%) crystallization results in formation of bcc-CoFe and $\mathrm{B}_{2} \mathrm{Co}_{3} \mathrm{Zr}$ phases. As the iron 

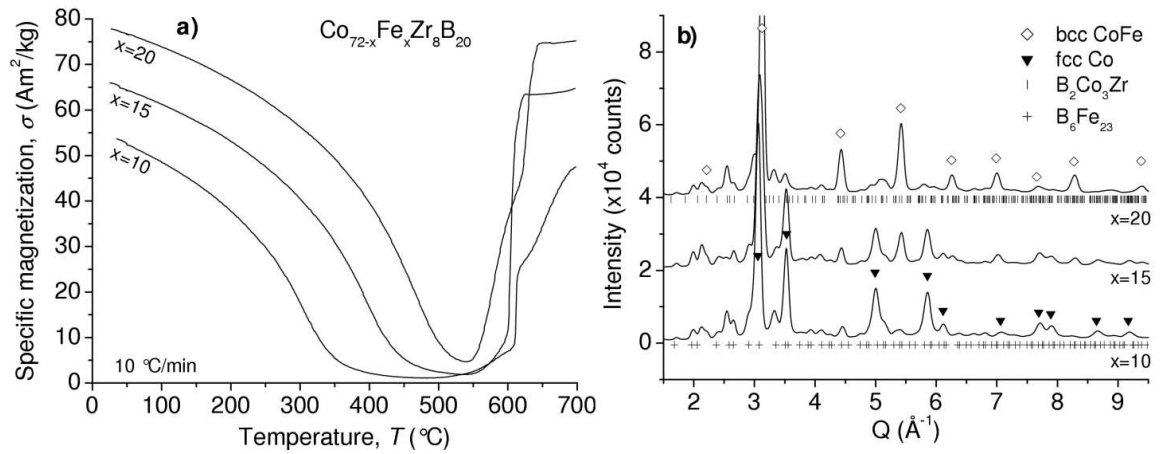

Fig. 2. (a) Thermomagnetic curves, $\sigma(T)$, of as-quenched CoFeZrB alloys. (b) XRD patterns collected on annealed samples after two heating runs up to $900^{\circ} \mathrm{C}$.

fraction decreases, fcc-Co and $\mathrm{B}_{6} \mathrm{Fe}_{23}$ are formed at the expenses of bcc-CoFe and $\mathrm{B}_{2} \mathrm{Co}_{3} \mathrm{Zr}$, respectively. Finally, the phase composition of the alloy with $x=10$ at.\% can be described as a mixture of fcc-Co and $\mathrm{B}_{6} \mathrm{Fe}_{23}$ phases with the small fraction of $\mathrm{B}_{2} \mathrm{Co}_{3} \mathrm{Zr}$ phase.

\section{Conclusions}

The as-quenched alloys $\mathrm{Co}_{72-x} \mathrm{Fe}_{x} \mathrm{Zr}_{8} \mathrm{~B}_{20}(x=10,15$, and 20 at.\%) prepared by rapid quenching are fully amorphous and soft magnetic. The addition of iron shifts the crystallization temperature and affects the phase composition of crystallized alloys. Furthermore it has positive influence on saturation magnetization and Curie temperature of amorphous phase, which tend to almost linearly increase with increasing the iron content.

\section{Acknowledgments}

This work was supported by the Science and Technology Assistance Agency under the contract No. APVT-20-008404 and by the Scientific Grant Agency of the Ministry of Education of Slovak Republic and the Slovak Academy of Sciences (VEGA1/4020/07).

\section{References}

[1] M.E. McHenry, M.A. Willard, D.E. Laughlin, Prog. Mater. Sci. 44, 291 (1999).

[2] A. Inoue, Acta Mater. 48, 279 (2000).

[3] A.P. Hammersley, S.O. Svensson, M. Hanfland, A.N. Fitch, D. Häusermann, High Press. Res. 14, 235 (1996). 